\title{
Review Article \\ History of the Tether Concept and Tether Missions: A Review
}

\author{
Yi Chen, ${ }^{1,2}$ Rui Huang, ${ }^{3}$ Xianlin Ren, ${ }^{1}$ Liping He, ${ }^{1}$ and Ye He ${ }^{4}$ \\ ${ }^{1}$ School of Mechanical, Electronic and Industrial Engineering, University of Electronic Science and Technology of China, \\ Chengdu 611731, China \\ ${ }^{2}$ School of Engineering and Built Environment, Glasgow Caledonian University, Glasgow G4 0BA, UK \\ ${ }^{3}$ School of Automation Engineering, University of Electronic Science and Technology of China, Chengdu 611731, China \\ ${ }^{4}$ The State Key Laboratory of Mechanical Transmission, Chongqing University, Chongqing 400044, China \\ Correspondence should be addressed to Yi Chen; leo.chen.yi@live.co.uk
}

Received 13 December 2012; Accepted 16 January 2013

Academic Editors: S. Koutchmy and W. W. Zeilinger

Copyright (C) 2013 Yi Chen et al. This is an open access article distributed under the Creative Commons Attribution License, which permits unrestricted use, distribution, and reproduction in any medium, provided the original work is properly cited.

\begin{abstract}
This paper introduces history of space tethers, including tether concepts and tether missions, and attempts to provide a source of references for historical understanding of space tethers. Several concepts of space tethers since the original concept has been conceived are listed in the literature, as well as a summary of interesting applications, and a research of space tethers is given. With the aim of implementing scientific experiments in aerospace, several space tether missions which have been delivered for aerospace application are introduced in the literature.
\end{abstract}

\section{Introduction}

With original concepts of "space elevator" or "beanstalk," space tethers were developed to transport payloads up and down without any propellant. A space tether is a kind of long cable ranging from a few hundred meters to many kilometers, which uses series of thin strands of high-strength fibre to couple spacecraft to each other or to other masses, and it also provides a mechanical connection which enables the transfer of energy and momentum from one object to the other.

Since the conception of space tether came up in the 19th century, it has not yet been fully utilised. Space tethers can be used in many applications, including the study of plasma physics and electrical generation in the upper atmosphere, the orbiting or deorbiting of space vehicles and payload, for interplanetary propulsion, and potentially for specialised missions, such as asteroid rendezvous, or in extreme form as the well-publicized space elevator. With the development of space technology, space tethers should be widely used in space exploration [1].

Space tethers have a long history since the original idea was proposed in 1895, and research work of space tethers quickly expanded, especially the research on dynamics and control of space tethers, which are the fundamentally aspects.
Furthermore, a series of tether missions have been delivered for aerospace applications in the last century. The aims of these missions are mostly for scientific experiments of space tethers' research [1-5].

\section{History of the Tether Concept}

The original idea of an orbital tower was first conceived by Konstantin Tsiolkovsky in $1895[6,7]$. Inspired by the Eiffel Tower, Tsiolkovsky imagined a giant tower reaching space with a "celestial castle" at the top, and the free-floating spindle-shaped tower- "Tsiolkovsky" tower, which is reaching from the surface of Earth to GSO. His proposal for a "Shuttle-borne Skyhook" for low orbital altitude research marked the advent of tethered satellite systems (TSS). It would be supported in tension by excess centrifugal force on the part of the tower beyond geosynchronous altitude. These were the first of a series of "space elevator" or "beanstalk" concepts having a tether in a synchronous orbit reaching all the way down to the ground. Payloads would be transported up and down the tether without the use of any propellant. This structure would be held in tension between Earth and the counterweight in space, like a guitar string held taut. Space elevators have also sometimes been referred to as beanstalks, 
space bridges, space lifts, space ladders, skyhook, orbital towers, or orbital elevators [8-10].

The first modern concept about space elevators was proposed as a nontechnical story in 1960 by another Russian scientist, Yuri Artsutanov. He suggested using a geostationary satellite as the base from which to deploy the structure downward. A cable would be lowered from geostationary orbit to the surface of the Earth by using a counterweight, which was extended from the satellite away from Earth, keeping the centre of gravity of the cable motionless relative to Earth. Artsutanov's idea was presented to the Russian-speaking public in an interview published in the Sunday Supplement of Komsomolskaya Pravda (usually translated as Komsomol Truth in English) in 1960, but was not available in English for a long time. He also proposed tapering the cable thickness to ensure that the tension in the cable was constant, this gives a thin cable at ground level, thickening up towards GSO [11-13].

Isaacs, Vine, Bradner, and Bachus, four American engineers, reinvented the concept, naming it a "Sky-hook," and published their analysis in the journal Science in 1966 [14]. They determined what type of material would be acceptable to build a space elevator, assuming it would be a straight cable with no variations in its cross section, and found that the strength required would be twice that of any existing material including graphite, quartz, and diamond $[13,15]$.

Colombo et al. provided an idea for a shuttle-borne skyhook for low-orbital altitude research in 1974 [16]. The concept finally came to the attention of the space flight engineering community through a technical paper written by Pearson [17] of the air force research laboratory in 1975. He designed a tapered cross section which would be better suited to building the elevator. The whole cable would be thickest at the geostationary orbit, where the tension was greatest, and would be narrowest at the tips so as to reduce the amount of weight per unit area of cross section that any point on the cable would have to bear. He suggested using a counterweight that would be slowly extended out to 144,000 kilometres as the lower section of the elevator was built. The upper portion of the cable would have to be longer than the lower without a large counterweight, due to the way in which gravitational and centrifugal forces change with distance from Earth. His analysis included disturbances such as the gravitation of the Moon, wind, and moving payloads up and down the cable. The weight of the material needed to build the elevator would have required thousands of space shuttle trips, although part of the material could be transported up the elevator when a minimum strength strand reached the ground, or it could be manufactured in space from asteroids [7].

In 1977, Moravec published an article named "A NonSynchronous Orbital Skyhook" [18], in which he proposed an alternative space elevator concept, using a rotating cable, and the rotation speed exactly matches the orbital speed in such a way that the instantaneous velocity, at the point where the cable was at the closest point to the Earth, was zero. This concept was an early version of a space tether transportation system.

Jerome Pearson discussed the concept of anchored lunar satellites in The Journal of the Astronautical Sciences in 1979, in which it was observed of anchored lunar satellites that they balanced about the collinear libration points of the EarthMoon system and attached to the lunar surface [19].

Also in 1979, space elevators were introduced to a broader audience with the simultaneous publication of Arthur C. Clarke's novel, "The Fountains of Paradise," in which engineers constructed a space elevator on top of a mountain peak in the fictional island country of Taprobane.

In 1984, a history of these concepts and their more modest derivatives was written by Tiesenhausen [20]. Carroll conducted some studies on the advantages of swinging and barely spinning systems $[21,22]$.

Since then, a series of interesting space tether applications have been proposed and analysed. Particularly in the last decade, the study of space tether has received significant attention from researchers covering a broad range of applications. Some examples of applications have considerable promise including the deployment and retrieval of subsatellites, aerobraking, electrodynamic boost, deorbit of satellites, and momentum-transfer with libration and rotation analysis. Control research on space tether applications was one of the most important aspects of space tether study, and each control method suited each application or mission requirement, such as liberation, oscillation, attitude, motion, and deployment [23].

\section{Tether Missions}

With the development of space technology, a series of missions have been delivered for aerospace application using tethered satellite systems over the past forty years. Many proposals were implemented including scientific experiments in the microgravity environment, upper atmospheric research, the generation of electricity, cargo transfer between orbiting bodies, collections of planetary dust, and the expansion of the geostationary orbit resource by tethered chain satellites. For example, National Aeronautics and Space Administration (NASA) has been developing tether technology for space applications since the 1960s, including electrodynamic tether propulsion, the Propulsive Small Expendable Deployer System (ProSEDS) flight experiment, "Hanging" momentum exchange tethers, rotating momentum exchange tethers, and tethers supporting scientific space research. Since then, a number of such tethers have already been flown on missions, including the Small Expendable-tether Deployer System (SEDS), the Tether Satellite System (TSS), the Tether Physics and Survivability experiment (TiPS), and the Space Technology Experiments (STEX). A brief tether mission history and the status of each one are shown in Table 1 [1, 7, 9, 21, 24-32].

The Gemini XI was a manned spaceflight in NASA's Gemini program, launched on September 12, 1966 [28]. It was the 9th manned Gemini flight, the 17th manned American flight, and the 25th spaceflight of all time, including X-15 flights, at altitudes of over $100 \mathrm{~km}$. The Gemini XI mission's main objectives were (1) rendezvous with the Gemini Agena Target Vehicle (GATV); (2) to conduct docking practice and extravehicular activity (EVA); (3) to conduct the eight scientific experiments: the synergistic effect of zero-g and radiation on white blood cells, the synoptic terrain photography, the synoptic weather photography, the nuclear emulsions, the 
TABLE 1: Tether mission history $[1,7,9,21,24-26,28,29]$.

\begin{tabular}{|c|c|c|c|c|c|}
\hline Mission & Year & Sponsor & Orbit & Length & Status \\
\hline Gemini XI & 1967 & NASA & LEO & $50 \mathrm{~m}$ & Launched \\
\hline Gemini XII & 1967 & NASA & LEO & $30 \mathrm{~m}$ & Launched \\
\hline TPE-1 & 1980 & NASA/ISAS & Suborbital & $400 \mathrm{~m}$ & Launched \\
\hline TPE-2 & 1981 & NASA/ISAS & Suborbital & $500 \mathrm{~m}$ & Launched \\
\hline TPE-3 (CHARGE-1) & 1983 & NASA/ISAS & Suborbital & $500 \mathrm{~m}$ & Launched \\
\hline CHARGE-2 & 1985 & NASA/ISAS & Suborbital & $500 \mathrm{~m}$ & Launched \\
\hline MAIMIK & 1986 & NASA/NDRE & LEO & $400 \mathrm{~m}$ & Launched \\
\hline ECHO-7 & 1988 & USAF & Suborbital & - & Launched \\
\hline OEDIPUS-A & 1989 & NRC/NASA/CRC/CSA & Suborbital & $958 \mathrm{~m}$ & Launched \\
\hline CHARGE-2B & 1992 & NASA/ISAS & Suborbital & $500 \mathrm{~m}$ & Launched \\
\hline TSS-1 (STS-46) & 1992 & NASA/ASI & LEO & $267 \mathrm{~m}$ & Launched \\
\hline SEDS-1 & 1993 & NASA & LEO & $20 \mathrm{~m}$ & Launched \\
\hline PMG & 1993 & NASA & LEO & $500 \mathrm{~m}$ & Launched \\
\hline SEDS-2 & 1994 & NASA & LEO & $20 \mathrm{~m}$ & Launched \\
\hline OEDIPUS-C & 1995 & NASA/NRC/CRC/CSA & Suborbital & $1 \mathrm{~km}$ & Launched \\
\hline TSS-1R (STS-75) & 1996 & NASA/ASI & LEO & $19.6 \mathrm{~km}$ & Launched \\
\hline TSS-2 (STS-75) & 1996 & NASA & LEO & $100 \mathrm{~m}$ & Cancelled \\
\hline TiPS & 1996 & $\mathrm{NRO} / \mathrm{NRL}$ & LEO & $4 \mathrm{~km}$ & Launched \\
\hline YES & 1997 & ESA/Delta-Utec & LEO & $35 \mathrm{~m}$ & Launched \\
\hline ATEx & 1999 & NRO/NRL & LEO & $22 \mathrm{~m}$ & Launched \\
\hline PICOSATs & 2000 & Aerospace corporation & LEO & $30 \mathrm{~m}$ & Launched \\
\hline MEPSI & 2002 & Aerospace corporation & LEO & $15.2 \mathrm{~m}$ & Launched \\
\hline ProSEDS & 2003 & NASA & LEO & $15 \mathrm{~m}$ & Cancelled \\
\hline MAST & 2007 & NASA/TUI/Stanford & LEO & $1 \mathrm{~km}$ & Launched \\
\hline YES2 & 2007 & ESA/Delta-Utec & LEO & $31.7 \mathrm{~m}$ & Launched \\
\hline STARS & 2009 & Kagawa university & LEO & $5 \mathrm{~m}$ & Launched \\
\hline T-REX & 2010 & ISAS/JAXA & LEO & $300 \mathrm{~m}$ & Launched \\
\hline TEPCE & 2013 & NRO/NRL & LEO & $1 \mathrm{~km}$ & Planning \\
\hline
\end{tabular}

airglow horizon photography, the UV astronomical photography, the Gemini ion wake measurement, and the dim sky photography; (4) synoptic terrain photography and a tethered vehicle test; (5) demonstrating automatic reentry and parking the GATV. All the Gemini XI mission's objectives were achieved, except the evaluation of the minimum reaction power tool, which was not performed because of the umbilical EVA was terminated prematurely.

The Gemini XII was a manned spaceflight in NASA's Gemini program launched on November 11, 1966. The major objectives were: (1) rendezvous, docking, and evaluation for the EVA; (2) tethered vehicle evaluation and experiments; (3) revolution rendezvous, docking, and automatic reentry demonstration; (4) docked maneuvering for a high-apogee excursion, docking practice, system tests, and GATV parking. All the objectives were achieved except the high-apogee excursion, because an anomaly was noted in the GATV primary propulsion system during insertion, and then the GATV's parking was not attempted because its attitude control gas was depleted [27, 29].

After the Gemini experiments, the first two experiments of the early 1980s were in 1980 and 1981, which were part of a joint program involving the Institute of Space and
Astronautical Science (ISAS) in Japan and the Centre for Atmospheric and Space Science of Utah State University. The project was called the Tethered Payload Experiment (TPE); the missions TPE-1 and TPE-2 were launched using two types of Japanese rockets, Kappa 9 M (flight H-9 M-69) and S-520 (flight S-520-2). From the Japanese Kagoshima Space Centre, the TPE-1 mission was launched via Kappa 9 M rocket on January 16, 1980. Its plan was to deploy 400 metres of cable, but its deployed cable was about 38 metres. The TPE-2 mission was launched on 29 January, 1981, and its tether was deployed to a distance about 65 metres $[7,26]$.

In 1983, the TPE-3 was planned by ISAS and Utah State University, which was also called CHARGE-1, and the tether length was about $500 \mathrm{~m}$. As the deployment system was improved, the tether deployed to its full length of 418 meters, and the tether was also found to act as a radio antenna for the electrical current through the cable. After that, CHARGE-2 was carried out as an international program between Japan and the USA using a NASA sounding rocket at White Sands Missile Range, in December 1985, its tether deployed to a length of 426 metres [7, 30].

The MAIMIK experiment was a joint mission by NASA and NDRE in 1986, for which the tether length was about 
$400 \mathrm{~m}$. This mission was designed to study the charging of an electron-beam emitting payload using a tethered motherdaughter payload configuration [31, 32].

In 1988, the US Air Force Geophysics Laboratory launched the Echo-7, which was designed to study the artificial electron beam propagation along magnetic field lines in space. The mission was designed to study how the artificial electron beam propagates along magnetic field lines in space $[7,33]$.

In 1989, the mission OEDIPUS-A was organised by the National Research Council of Canada (NRC), NASA, and some other partners, in which a conducting tether was deployed over 958 metres during the flight of a Black Brant sounding rocket into the auroral ionosphere [7, 34].

With similar equipment to that on CHARGE-2, the CHARGE-2B tethered rocket mission was launched in 1992 by NASA with a Black Brant V rocket. The mission was to generate electromagnetic waves by modulating the electron beam. The tether was fully deployed over 400 meters and the experiments all worked as planned $[7,35]$.

The following OEDIPUS mission was the OEDIPUS-C tethered payload mission, which was launched in 1995 with an 1174-metre deployed tether, and a Tether Dynamics Experiment (TDE) was also included as a part of the OEDIPUS-C $[7,36]$.

The first orbital flight experiment with a long tether was the Tethered Satellite System (TSS) mission, launched on the Space Shuttle in July 1992. The Tethered Satellite System-1 (TSS-1) was flown during STS-46, aboard the Space Shuttle Atlantis, from July 31 to August 8, 1992. The TSS-1 mission discovered a lot about the dynamics of the tethered system. Although the satellite was deployed only 260 metres, it was able to show that the tether could be deployed, controlled, and retrieved, and that the TSS was easy to control, and even more stable than predicted. The TSS was an electrodynamic tether, its deployment mechanism jammed resulting in tether sever and less than 1000 metres of deployment. The objectives of TSS-1 were (1) to verify the performance of the TSS equipment; (2) to study the electromagnetic interaction between the tether and the ambient space plasma; (3) to investigate the dynamical forces acting on a tethered satellite. In the first tether deployment, when the satellite was moving excessively from side to side, the deployment was aborted. The second trial of deployment was unreeled to a length of 260 metres $[7,37-41]$.

The Shuttle Electrodynamic Tether System (SETS) experiment formed part of the scientific experiments comprising the first flight of the NASA/ASI Tethered-Satellite System flown at an altitude of $300 \mathrm{~km}$ and at an orbital inclination of 28.5 degrees in July/August 1992. The SETS experiment was designed to study the electrodynamic behaviour of the Orbiter-Tether-Satellite system, as well as to provide background measurements of the ionospheric environment near the Orbiter. The SETS experiment was able to operate continuously during the mission thereby providing a large data set. Details of the SETS objectives, its instrumentation, and initial results from the mission highlighting voltage, current, and charging measurements were presented [42].
The Small Expendable Deployer System-1 (SEDS-1) was launched from Cape Canaveral Air Force Station as a Delta/GPS secondary payload in 1993. As a secondary payload on a Delta II launch vehicle, SEDS-1 was the first successful 20-kilometre space-tether experiment. When $1 \mathrm{~km}$ of tether remained, active braking was applied by wrapping the tether around a "barber pole" brake. Finally, the braking system and sensors did not work as predicted, resulting in hard stop/endmass recoil at deployment completion [23].

In 1996, the Plasma Motor Generator (PMG) was launched by NASA. This was an electrodynamic tether, which could assess the effectiveness of using hollow cathode assemblies to deploy an ionised gas, and to "ground" electrical currents by discharging the energy to space. An early experiment used a 500 metre conducting tether. When the tether was fully deployed during this test, it generated a potential of 3,500 volts. This conducting single-line tether was severed after five hours of deployment. It was believed that the failure was caused by an electric arc generated by the conductive tether's movement through the Earth's magnetic field. The PMG flight demonstration proved the ability of the proposed Space Station plasma grounding techniques in maintaining the electrostatic potential between the Space Station and the surrounding plasma medium. The PMG also demonstrated the ability to use electrostatic tethers to provide thrust to offset drag in LEO space systems, and it demonstrated the use of direct magnetic (nonrocket) propulsion for orbital maneuvering [23].

The Small Expendable Deployer System-2 (SEDS-2) was launched on the last GPS Block 2 satellite in 1994. The SEDS-2 used feedback braking, which was started early in deployment. This limited the residual swing after deployment to 4 degrees. Mission success was defined as deployment of at least $18 \mathrm{~km}$, plus a residual swing angle of less than 15 degrees. The SEDS-2 had an improved braking system compared to SEDS-1, which was a feedback control system and applied braking force as a function of the measured speed of the unrolling tether. This was to ensure that the satellite stopped flying out just when the whole tether was deployed and to prevent the bounces experienced during the previous mission [7].

In 1996, the Tethered Satellite System Reflight (TSS-1R) was carried by using US space shuttle STS-75 successfully. The primary objective of STS-75 was to carry the Tethered Satellite System Reflight (TSS-1R) into orbit and to deploy it spacewards on a conducting tether. The mission also flew the United States Microgravity Payload (USMP-3), which was designed to investigate materials science and condensed matter physics. The TSS1-R mission objectives were (1) to characterise the current-voltage response of the TSS-orbiter system; (2) to characterise the satellite's high-voltage sheath structure and current collection process; (3) to demonstrate electric power generation; (4) to verify tether control laws and basic tether dynamics; (5) to demonstrate the effect of neutral gas on the plasma sheath and current collection; (6) to characterise the TSS radio frequency and plasma wave emissions; (7) to characterise the TSS dynamic-electrodynamic coupling $[43,44]$. 
The Tether Physics and Survivability Experiment (TiPS) was deployed on June 20, 1996 at an altitude of 1,022 kilometres as a project of the US Naval Research Laboratory. The satellite was a tether physics experiment consisting of two end masses connected by a $4 \mathrm{~km}$ nonconducting tether, for which the two tethered objects were called "Ralph" and "Norton." This experiment was designed to increase knowledge about gravity-gradient tether dynamics and the survivability of tethers in space [45].

The first Young Engineers' Satellite (YES-1) programme was completed on November 3, 1997. It was designed to operate with a $35 \mathrm{~km}$ tether deployment, but the mission was cancelled before the flight when the launch authority changed the nominal Ariane orbit. In the new orbit configuration, a deployed $35 \mathrm{~km}$ tether would have constituted a hazard to the satellites in LEO [46].

The Advanced Tether Experiment (ATEx) was launched into orbit aboard the National Reconnaissance Office (NRO) sponsored by Space Technology Experiment spacecraft (STEX) on October 3, 1998. ATEx was intended to demonstrate the deployment and survivability of a novel tether design, as well as being used for controlled libration maneuvers. On January 16, 1999, after a deployment of only $22 \mathrm{~m}$ of tether, ATEx was jettisoned from STEX due to an out-of-limit condition sent by the experiment's tether angle sensor. The ATEx lower end mass was jettisoned from the host spacecraft and the tethered upper and lower end masses freely orbited the Earth in a demonstration of long-term tether survivability. The ATEx was a tethered satellite experiment with the following mission objectives: (1) deployment of a novel, nonconductive polyethylene tape tether; (2) verification of dynamical models of deployment and orbital libration; (3) ejection of the ATEx lower end mass from the host spacecraft [47].

The PICOSAT mission was launched on September 30, 2001. It was a real-time tracking satellite of the miniaturised picosatellite satellite series. The name "PICO" combined the first letters of all the four of its experiments, which were the Polymer Battery Experiment (PBEX), the Ionospheric Occultation Experiment (IOX), the Coherent Electromagnetic Radio Tomography (CERTO), and the On Orbit Mission Control (OOMC) [48]. A pair of $0.25 \mathrm{~kg}$ MEMS picosatellites with an intersatellite communications experiment were included in this mission and were connected by a 30 metre tether [48].

The MEPSI series (Micro Electro-Mechanical Systemsbased PicoSat Inspector) was a pair of tethered picosatellites, based on the CubeSat design, launched by a custom deployer aboard the STS-113 Endeavour mission on December 2, 2002. The spacecrafts were manufactured for the Defense Advanced Research Projects Agency (DARPA) by the Aerospace corporation in collaboration with NASA's Jet Propulsion Laboratory (JPL). The two spacecrafts were cubic in shape, of mass $1 \mathrm{~kg}$ each, and were connected via a $15.2 \mathrm{~m}$ tether in order to facilitate detection and tracking via ground-based radar [48].

The Propulsive Small Expendable Deployer System (ProSEDS) was a NASA space tether propulsion experiment intended to be a followup to SEDS. It was originally intended to be flown along with a launch of a Global Positioning
System (GPS) satellite in the spring of 2003, but was cancelled at the last moment, due to concerns that the tether might collide with the international space station [49].

The Multi-Application Survivable Tether (MAST) experiment was launched into LEO on April 17, 2007, in which the $1 \mathrm{~km}$ multistrand interconnected tether (Hoytether) was intended to test and prove the long-term survivability of tethers in space, but the tether failed to deploy. The experiment hardware was designed under a NASA Small Business Technology Transfer (STTR) collaboration between Tethers Unlimited Inc (TUI) and Stanford University, with TUI developing the tether, the tether deployer, the tether inspection subsystem, the satellite avionics, and the software system, and Stanford students developing the satellite structures and assisting with the avionics design [50].

The second Young Engineers Satellite (YES2) was launched on September 14, 2007. It was a technology demonstration project designed to test and produce data for the "Space Mail" concept, wherein a tether was used to return material from space to Earth, instead of by conventional chemical propulsion. YES2 aimed to demonstrate a tether-assisted reentry concept, whereby the payload would be returned to Earth using momentum provided from a swinging tether. Deployment was intended to take place in two phases: (1) deployment of $3.5 \mathrm{~km}$ of tether to the local vertical and hold and (2) deployment to $30 \mathrm{~km}$ for a swinging cut. The measured altitude gain of the Fonton-M3 corresponded with what simulations showed would have happened if $31.7 \mathrm{~km}$ of tether were extended, another strong indication that the YES2 tether had in fact been fully depolyed.

The YES-2 mission was very nearly a complete success becouse of the following: (1) the entire record-breaking length of tether has been deployed; (2) Fotino rocket seemed to have been deorbited by using momentum exchange; (3) plentiful data has been gathered on tether deployment, dynamics and deorbiting, which may lead to an operational way of returning capsules without any form of propulsion $[7,51,52]$.

On January 23, 2009, a space tether mission called "The Space Tethered Autonomous Robotic Satellite (STARS)," developed by Kagawa Satellite Development Project at Kagawa University, was launched as a secondary payload aboard H-IIA flight. The satellite was named KUKAI after launch and based on a "cubesat" platform like MAST, and consisted of two subsatellites, "Ku" and "Kai," which are linked by a 5-meter tether. The separation of the rocket and satellite and the transfer into the planned orbit were successful, but the tether-only deployed to a length of several centimeters because of the launch lock trouble of the tether reel mechanism [53].

Tether Technologies Rocket Experiment (T-REX) mission, sponsored by the Japanese Aerospace Exploration Agency (ISAS/JAXA), was launched August 31, 2010, on sounding rocket S-520-25 from Uchinoura Space Center, reaching a maximum altitude of $309 \mathrm{~km}$. T-Rex was developed by the Kanagawa Institute of Technology/Nihon University, which led an international team to test a new type of electrodynamic tether (EDT) that may lead to a generation of propellantless propulsion systems for LEO spacecraft. The tether was 300 metres long and deployed as planned, a 
video of deployment was transmitted to the ground. Tether deployment was verified successfully, as was the fast ignition of a hollow cathode in the space environment [54].

Tether Electrodynamic Propulsion CubeSat Experiment (TEPCE) mission, planned by Naval Research Laboratory, is an electrodynamic tether experiment based on a "triple cubesat" configuration. This experiment is currently planned for launch as a secondary payload in September 2013. Two nearly identical endmasses with a stacer spring between them are used in TEPCE, which separate the endmass and start deployment of a $1 \mathrm{~km}$ long braided-tape conducting tether. TEPCE will use a passive braking to reduce speed and hence recoil at the end of electrodynamic current in either direction. The main purpose of this mission is to raise or lower the orbit by several kilometres per day, to change libration state, to change orbit plane, and to actively maneuver [55].

\section{Conclusions}

This literature review has attempted to provide the interested reader with a historical review of space tethers. Two main topics in space tethers history are introduced, including tether concepts and tether missions. As has been shown, many novel space tether concepts were proposed since the original concept of space tether was conceived. Furthermore, many related research and application studies have been presented, such as dynamics, control, and deployment of space tethers. The paper also covers a series of tether missions which have been delivered for aerospace application using tethered satellite systems. Most of these tether missions show that space tethers are fruitful for the future development of aerospace technologies.

\section{Acknowledgments}

The authors would like to acknowledge the partial supports provided by the National Natural Science Foundation of China (no. 51105061, 61273256, 61179059, 50905028, and 51275077), the Scientific Research Foundation for the Returned Overseas Chinese Scholars, State Education Ministry (no. 201294001), the Fundamental Research Funds for the Central Universities (no. ZYGX2012J104), and the Overseas Research Students Awards Scheme (ORSAS) awarded by the University of Glasgow and the scholarship awarded by the Faculty of Engineering, University of Glasgow. Also, the authors would like to acknowledge three anonymous reviewers for their valuable comments for this paper.

\section{References}

[1] M. P. Cartmell and D. J. McKenzie, "A review of space tether research," Progress in Aerospace Sciences, vol. 44, no. 1, pp. 1-21, 2008.

[2] A. K. Misra and V. J. Modi, "Dynamics and control of tether connected two-body systems-a brief review," International Astronautical Congress, pp. 219-236, 1982.

[3] A. K. Misra and V. J. Modi, "A survey on the dynamics and control of tethered satellite systems," in Proceedings of NASA/AIAA/ PSN International Conference on Tethers, Arlington, Va, USA, September 1986.
[4] M. J. Eiden and M. P. Cartmell, "Overcoming the challenges: tether systems roadmap for space transportation applications," in Proceedings of the AIAA/ICAS International Air and Space Symposium and Exposition, 2003.

[5] K. D. Kumar, "Review of dynamics and control of nonelectrodynamic tethered satellite systems," Journal of Spacecraft and Rockets, vol. 43, no. 4, pp. 705-720, 2006.

[6] J. A. Angelo, Space Technology, Greenwood Publishing, Westport, Conn, USA, 2003.

[7] M. V. Pelt, Space Tethers and Space Elevators, Springer, Berlin, Germany, 2009.

[8] D. F. Dickinson and W. C. Straka, "Tethered satellite antenna arrays for passive radar systems," in Proceedings of the IEEE Aerospace Applications Conference Digest, pp. 117-125, February 1990.

[9] J. A. Carroll and J. C. Oldson, "Tethers for small satellite applications," in Proceedings of the AIAA/USU Small Satellite Conference, 1995.

[10] S. Price, Audacious and Outrageous: Space Elevators, NASA Science News, 2000.

[11] V. V. Beletsky and E. M. Levin, Dynamics of Space Tether Systems, Advances in the Astronautical Sciences, American Astronautical Society, Washington, DC, USA, 1993.

[12] B. C. Edwards and E. A. Westling, The Space Elevator: A Revolutionary Earth-to-Space Transportation System, Spageo, San Francisco, Calif, USA, 2003.

[13] M. J. Laine, B. Fawcett, and T. Nugent, Liftport: The Space Elevator-Opening Space to Everyone, Meisha Merlin Publishing, New York, NY, USA, 2006.

[14] J. D. Isaacs, A. C. Vine, H. Bradner, and G. E. Bachus, "Satellite elongation into a true "sky-hook",' Science, vol. 151, no. 3711, pp. 682-683, 1966.

[15] P. Ragan and B. Edwards, Leaving the Planet by Space Elevator, Lulu.com, Raleigh, NC, USA, 2006.

[16] G. Colombo, E. M. Gaposchkin, M. D. Grossi, and G. C. Weiffenbach, "The sky-hook: a shuttle-borne tool for low-orbitalaltitude research," Meccanica, vol. 10, no. 1, pp. 3-20, 1975.

[17] J. Pearson, "The orbital tower: a spacecraft launcher using the Earth's rotational energy," Acta Astronautica, vol. 2, no. 9-10, pp. 785-799, 1975.

[18] H. Moravec, "A non-synchronous orbital skyhook," Journal of the Astronautical Sciences, vol. 25, no. 4, pp. 307-322, 1977.

[19] J. Pearson, "Anchored lunar satellites for cislunar transportation and communication," Journal of the Astronautical Sciences, vol. 27, no. 1, pp. 39-62, 1979.

[20] G. Tiesenhausen, "Tether in space: birth and growth of a new avenue to space utilization," Tech. Rep. NASA-TM-82571, NASA, Huntsville, Ala, USA, 1984.

[21] J. A. Carroll, "Guidebook for analysis of tether applications," NASA Contractor Report NASA CR-178904, 1985.

[22] J. A. Carroll, “Tether applications in space transportation,” Acta Astronautica, vol. 13, no. 4, pp. 165-174, 1986.

[23] M. L. Cosmo and E. C. Lorenzini, Tethers in Space Handbook, NASA Marshall Space Flight Center, Huntsville, Ala, USA, 3rd edition, 1997.

[24] L. Johnson, B. Gilchrist, R. D. Estes, and E. Lorenzini, “Overview of future NASA tether applications," Advances in Space Research, vol. 24, no. 8, pp. 1055-1063, 1999.

[25] J. A. Carroll, Space Transport Development Using Orbital Debris, Tether Applications, Chula Vista, Calif, USA, 2002. 
[26] H. Klinkrad, Space Debris: Models and Risk Analysis, Springer, Berlin, Germany, 2006.

[27] D. Darling, The Complete Book of Spaceflight: From Apollo 1 to Zero Gravity, John Wiley \& Sons, New York, NY, USA, 2002.

[28] “NASA Gemini 11,” NSSDC ID: 1966-081A, 1966, http://nssdc .gsfc.nasa.gov/.

[29] T. Furniss, D. Shayler, and M. D. Shayler, Praxis Manned Spaceflight Log 1961-2006, Springer, Berlin, Germany, 2007.

[30] N. Kawashima, S. Sasaki, K. I. Oyama et al., "Results from a tethered rocket experiment (Charge-2)," Advances in Space Research, vol. 8, no. 1, pp. 197-201, 1988.

[31] B. N. Maehlum, J. Troim, N. C. Maynard et al., "Studies of the electrical charging of the tethered electron accelerator motherdaughter pocket maimik," Geophysical Research Letters, vol. 15, pp. 725-728, 1988.

[32] W. F. Denig, B. N. Maehlum, and K. A. Svenes, "Review of the maimik rocket experiment," Space Tethers for Science in the Space Station Era, vol. 2, pp. 443-456, 1989.

[33] R. J. Nemzek and J. R. Winckler, "Immediate and delayed highenergy electrons due to Echo 7 accelerator operation," Space Tethers for Science in the Space Station Era, vol. 2, pp. 466-490, 1989.

[34] H. G. James, "Wave results from OEDIPUS A," Advances in Space Research, vol. 13, no. 10, pp. 5-13, 1993.

[35] E. M. Levin, Dynamic Analysis of Space Tether Missions, American Astronautical Society, Washington, DC, USA, 2007.

[36] P. Prikryl, H. G. James, and D. J. Knudsen, "OEDIPUS-C topside sounding of an auroral E region," Advances in Space Research, vol. 24, no. 8, pp. 1065-1068, 1999.

[37] C. Bonifazi, G. Manarini, J. Sabbagh et al., "Tethered-satellite system (TSS): preliminary results on the active experiment core equipment," Il Nuovo Cimento C, vol. 16, no. 5, pp. 515-538, 1993.

[38] M. Malerba, "The first mission of the tethered statellite," Il Nuovo Cimento C, vol. 16, no. 5, pp. 485-494, 1993.

[39] R. S. Ryan, D. K. Mowery, and D. D. Tomlin, "The Dynamic Phenomena of a Tethered Satellite-NASA's First Tethered Satellite Mission (TSS-1)," 1993, http://nla.gov.au/nla.cat-vn4066740.

[40] S. Bergamaschi, F. Bonon, P. Merlina, and M. Morana, "Theoretical and experimental investigation of TSS-1 dynamics," Acta Astronautica, vol. 34, no. C, pp. 69-82, 1994.

[41] M. Dobrowolny and N. H. Stone, "A technical overview of TSS1: the first Tethered-satellite system mission," Il Nuovo Cimento C, vol. 17, no. 1, pp. 1-12, 1994.

[42] V. Aguero, P. M. Banks, B. Gilchrist et al., "The Shuttle Electrodynamic Tether System (SETS) on TSS-1," Il Nuovo Cimento C, vol. 17, no. 1, pp. 49-65, 1994.

[43] C. George, Tethered Satellite System Reflight (TSS-1R) Post-Flight Engineering Performance Report, Marshall Space Flight Center, Huntsville, Ala, USA, 1996.

[44] N. H. Stone, W. J. Raitt, and K. H. Wright, "The TSS-1R electrodynamic Tether experiment: scientific and technological results," Advances in Space Research, vol. 24, no. 8, pp. 1037-1045, 1999.

[45] W. J. Barnds, S. Coffey, M. Davis et al., "TiPS: results of a tethered satellite experiment," in Proceedings of the AASI/AIAA Astrodynamics Conference, 1997.

[46] E. J. van der Heide and M. Kruijff, "Tethers and debris mitigation," Acta Astronautica, vol. 48, no. 5-12, pp. 503-516, 2001.

[47] S. Koss, "Tether deployment mechanism for the advanced tether experiment (ATEX)," in Proceedings of European Space Mechanism and Tribology Symposium, pp. 175-182, 1997.
[48] R. Osiander, M. A. G. Darrin, and J. Champion, MEMS and Microstructures in Aerospace Applications, CRC Press, Boca Raton, Fla, USA, 2005.

[49] J. A. Vaughn, L. Curtis, B. E. Gilchrist, S. G. Bilén, and E. C. Lorenzini, "Review of the proseds electrodynamic tether mission development," in Proceedings of the 40th AIAA/ASME/ SAE/ASEE Joint Propulsion Conference and Exhibit, July 2004.

[50] R. Hoyt, J. Slostad, and R. Twiggs, "The multi-application survivable tether (MAST) experiment," in Proceedings of the AIAA/ASME/SAE/ASEE Joint Propulsion Conference and Exhibit, pp. 20-23, 2003.

[51] S. Dueck, N. Gadhok, M. Kinsner, J. Kraut, T. Tessier, and W. Kinsner, "YES2 DHS: a space tether control subsystem," in Proceedings of the Canadian Conference on Electrical and Computer Engineering: Toward a Caring and Humane Technology (CCECE '03), pp. 1287-1292, May 2003.

[52] P. Williams, A. Hyslop, M. Stelzer, and M. Kruijff, "YES2 optimal trajectories in presence of eccentricity and aerodynamic drag," Acta Astronautica, vol. 64, no. 7-8, pp. 745-769, 2009.

[53] M. Nohmi, "Mission design of a tethered robot satellite "STARS" for orbital experiment," in Proceedings of the IEEE International Conference on Control Applications (CCA '09), pp. 1075-1080, July 2009.

[54] H. A. Fujii, T. Watanabe, H. Kojima et al., "Sounding rocket experiment of bare electrodynamic tether system," Acta Astronautica, vol. 64, no. 2-3, pp. 313-324, 2009.

[55] S. Coffey, B. Kelm, A. Hoskin, J. Carroll, and E. Levin, “Tetheres elctrodynamic propulsion CubeSat experiment (TEPCE)," in Proceedings of Air Force Orbital Resources Ionosphere Conference, pp. 12-14, 2010. 

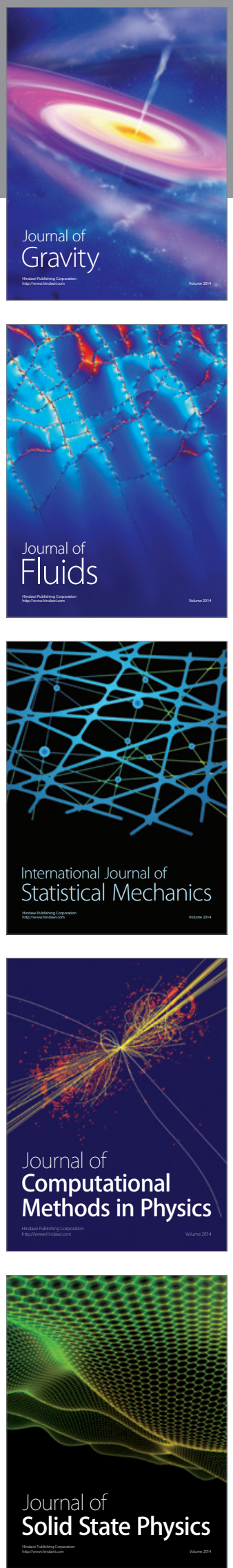

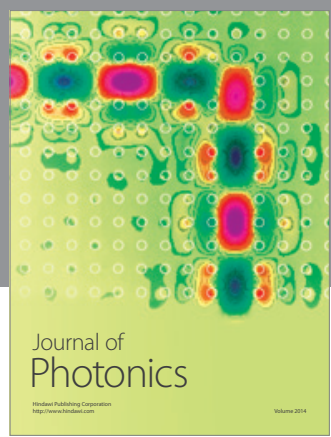

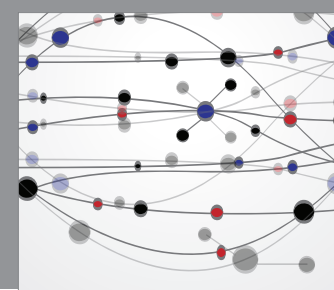

The Scientific World Journal

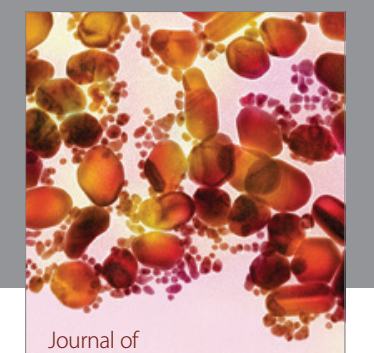

Soft Matter
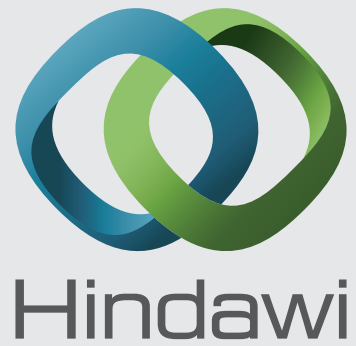

Submit your manuscripts at

http://www.hindawi.com
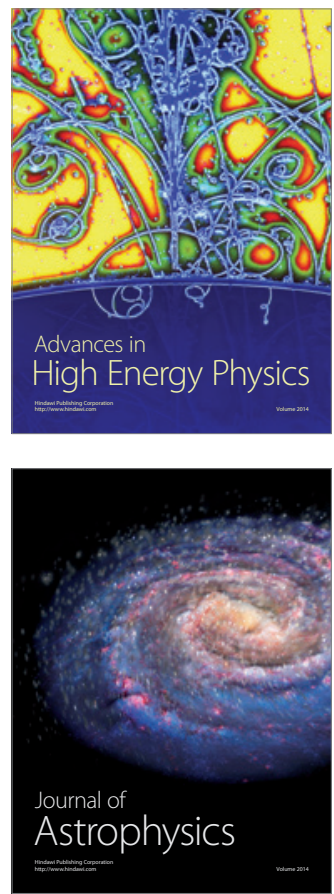
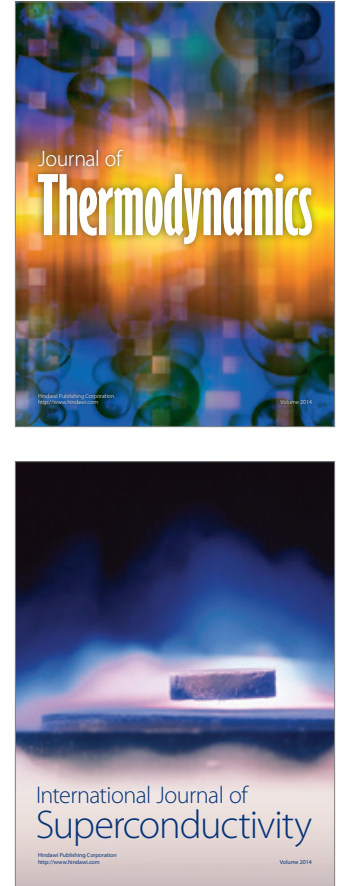
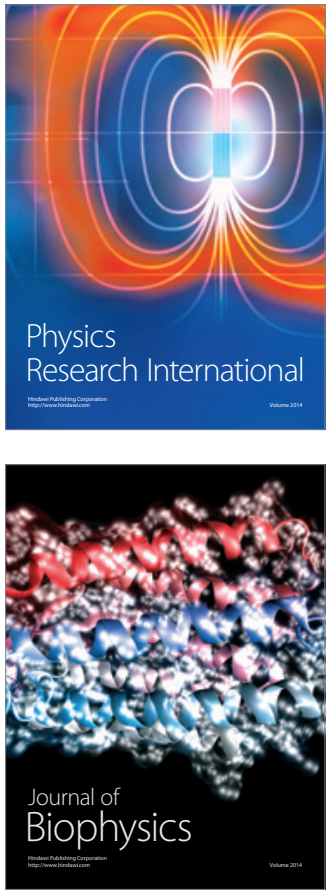
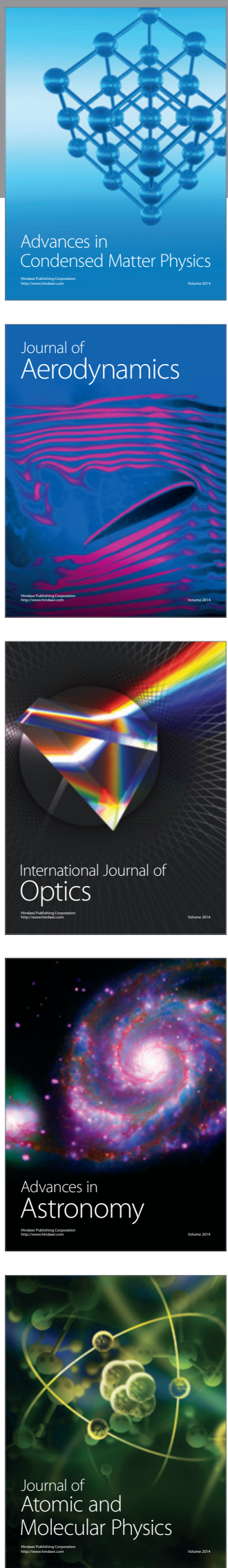